\title{
The butterfly effect: From Seldinger technique to endovascular arch repair
}

\author{
Grayson H. Wheatley III, MD, FACS
}

\author{
From the Division of Cardiovascular Surgery, Temple University School of Medicine, Philadelphia, Pa. \\ Disclosures: Author has nothing to disclose with regard to commercial support. \\ Received for publication June 30, 2016; accepted for publication July 1, 2016; available ahead of print July 26 , \\ 2016. \\ Address for reprints: Grayson H. Wheatley III, MD, FACS, Division of Cardiovascular Surgery, Lewis Katz \\ School of Medicine at Temple University, 3401 N Broad St, 3rd Floor, Zone C, Suite 301, Philadelphia, PA \\ 19147 (E-mail: grayson.wheatley@tuhs.temple.edu). \\ J Thorac Cardiovasc Surg 2016;152:1307-8 \\ $0022-5223 / \$ 36.00$ \\ Copyright (c) 2016 by The American Association for Thoracic Surgery \\ http://dx.doi.org/10.1016/j.jtcvs.2016.07.007
}

The endovascular revolution was initiated in 1953, when Seldinger ${ }^{1}$ published his seminal work describing a novel technique for percutaneous catheter insertion into the cardiovascular system. A virtual downstream cascade of endovascular techniques and technologies ensued as a result of this paradigm-changing technique. In 1962, Dr Edward Lorenz, a meteorologist from the Massachusetts Institute of Technology, gave a presentation at the 139th meeting of the American Association for the Advancement of Sciences entitled, "Deterministic Nonperiodic Flow," which was subsequently published in $1963 .^{2}$ Later known as the "butterfly effect," the revolutionary principles regarding systems' behavior changed the way we understood the equilibrium of systems relative to a seemingly innocuous perturbation in the system. In essence, Seldinger's technique was the endovascular equivalent (disrupter of cardiovascular therapies) of a butterfly flapping its wings and subsequently inciting a complex set of the atmospheric perturbations leading to a resulting hurricane in another part of the distant atmosphere. As a central tenet of chaos theory, the butterfly effect can just as easily describe the ongoing explosion of endovascular treatments, including transcatheter valve and endovascular aortic repair procedures.

In this issue of the Journal, Canaud and colleagues ${ }^{3}$ describe their homemade technique of creating a proximal scallop in a thoracic aortic stent graft to facilitate zone 2 aortic arch repair. This creative technique preserves patency to the great vessels through the scalloped portion of the aortic stent graft (oriented along the outer curve of the aortic arch) while allowing significantly more proximal seal zone along the inner curve. The simple elegance of this approach is that it avoids the technical challenges associated with cannulating the great vessels, which has been shown to increase the stroke risk and procedural time (and associated radiation exposure and intraarterial contrast administration). Furthermore, the average back-table time to modify an existing thoracic aortic

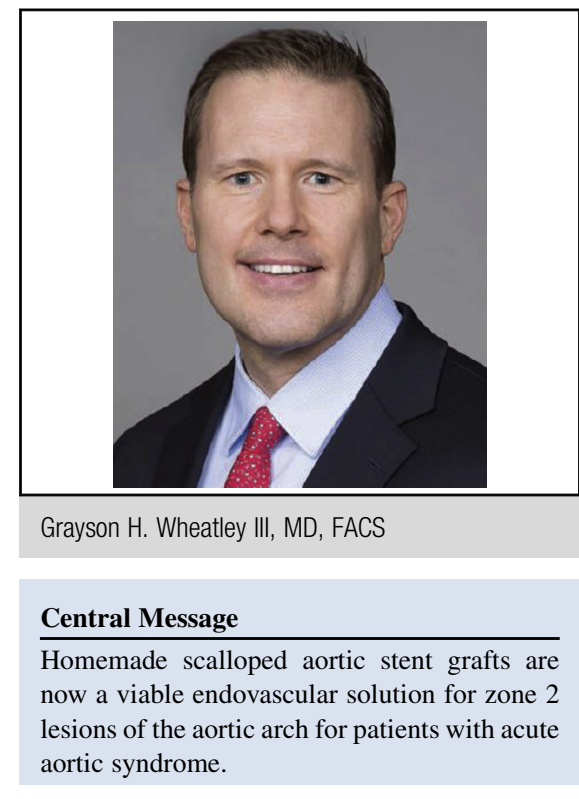

See Article page 1301.

stent graft was 15 minutes in the study of Canaud and colleagues. $^{3}$ Thus the customization option described in this article facilitates off-the-shelf accessibility for the emergency treatment of patients who, because of the gravity of their acute aortic syndrome, are unable to wait for a customized, made-to-order, branched aortic stent graft.

Currently, there are several endovascular options for treating acute aortic syndrome of the aortic arch. Hybrid arch repair, chimney grafts of the aortic arch, and branched aortic stent grafts have been described for patients with aortic arch disease. ${ }^{4-6}$ Each of these techniques has its advantages and disadvantages and may be overly extensive for patients with zone 2 lesions of the aortic arch. Another distinct advantage of the homemade scallop technique is that, as Canaud and colleagues ${ }^{3}$ have demonstrated, this approach can be applied to a number of aortic pathologies other than aneurysms, including aortic dissections.

In summary, the homemade scallop approach to thoracic aortic stent grafts can be applied to patients with zone 2 aortic arch lesions to preserve great vessel flow in a straightforward and feasible manner. Industry will need to continue the successful track record of innovation to provide an off-the-shelf version of the scalloped grafts to 
avoid some of the pitfalls associated with modifying aortic stent grafts on the back table. The metamorphosis of endovascular approaches to the aortic arch is more than a chaotic process left to chance but rather is truly as predictable as the butterfly effect-aptly renamed as the "endovascular effect."

\section{References}

1. Seldinger SI. Catheter replacement of the needle in percutaneous arteriography; a new technique. Acta Radiol. 1953;39:368-76.
2. Lorenz EN. Deterministic nonperiodic flow. J Atmosph Sci. 1963;20:130-41.

3. Canaud L, Gandet T, Khantalin I, Ozdemir BA, Marty-Ané CH, Alric P. Homemade proximal scalloped graft for thoracic endovascular aortic repair of zone 2 acute aortic syndrome. J Thorac Cardiovasc Surg. 2016;152:1301-6.

4. Koullias GJ, Wheatley GH III. State-of-the-art hybrid procedures for the aortic arch: a meta-analysis. Ann Thorac Surg. 2010;90:689-97.

5. Baldwin ZK, Chuter TA, Hiramoto JS, Reilly LM, Schneider DB. Double-barrel technique for preservation of aortic arch branches during thoracic endovascular aortic repair. Ann Vasc Surg. 2008;22:703-9.

6. Roselli EE, Arko FR III, Thompson MM, Valiant Mona LSA Trial Investigators. Results of the Valiant Mona LSA early feasibility study for descending thoracic aneurysms. J Vasc Surg. 2015;62:1465-7.e3. 